\title{
Comparison of the Effectiveness of Three Lumbosacral Orthoses on Early Spine Surgery Patients: A Prospective Cohort Study
}

\author{
Soo Woong Jang, $\mathrm{MD}^{1}$, Hee Seung Yang, $\mathrm{MD}^{1}$, Young Bae Kim, MD, PhD², Joo Chul Yang, MD³ ${ }^{3}$ Kyu Bok
} Kang, $\mathrm{MD}^{2}$, Tae Wan Kim, $\mathrm{MD}^{3}$, Kwan Ho Park, $\mathrm{MD}^{3}$, Kyung Soo Jeon, $\mathrm{MD}^{1}$, Hee Dong Shin, $\mathrm{MD}^{1}$, Ye Eun Kim, $\mathrm{RN}^{3}$, Han Na Cho, $\mathrm{RN}^{2}$, Yun Kyung Lee, $\mathrm{RN}^{1}$, Young Lee, $\mathrm{MS}^{4}$, Seul Bin Na Lee, $\mathrm{MS}^{4}$, Dong Young Ahn, $\mathrm{CPO}^{5}$, Woo Sob Sim, $\mathrm{CPO}^{5}$, Min Jo, $\mathrm{CPO}^{5}$, Gyu Jik Jo, $\mathrm{CPO}^{5}$, Dong Bum Park, $\mathrm{CPO}^{5}$, Gwan Su Park, $\mathrm{CPO}^{5}$

Departments of ${ }^{1}$ Rehabilitation Medicine, ${ }^{2}$ Orthopedic Surgery, and ${ }^{3}$ Neurosurgery, Veterans Health Service Medical Center, Seoul; ${ }^{4}$ Veterans Medical Research Institute, Veterans Health Service Medical Center, Seoul; ${ }^{5}$ Center of Prosthetics and Orthotics, Veterans Health Service Medical Center, Seoul, Korea

\begin{abstract}
Objective To compare the convenience and effectiveness of the existing lumbosacral orthoses (LSO) (classic LSO and Cybertech) and a newly developed LSO (V-LSO) by analyzing postoperative data.

Methods This prospective cohort study was performed from May 2019 to November 2019 and enrolled and analyzed 88 patients with degenerative lumbar spine disease scheduled for elective lumbar surgery. Three types of LSO that were provided according to the time of patient registration were applied for 6 weeks. Patients were randomized into the classic LSO group ( $\mathrm{n}=31$ ), Cybertech group $(\mathrm{n}=26)$, and V-LSO group ( $\mathrm{n}=31)$. All patients were assessed using the Oswestry Disability Index (ODI) preoperatively and underwent plain lumbar radiography (anteroposterior and lateral views) 10 days postoperatively. Lumbar lordosis (LS angle) and frontal imbalance were measured with and without LSO. At the sixth postoperative week, a follow-up assessment with the ODI and orthosis questionnaire was conducted.

Results No significant differences were found among the three groups in terms of the LS angle, frontal imbalance, ODI, and orthosis questionnaire results. When the change in the LS angle and frontal imbalance toward the reference value was defined as a positive change with and without LSO, the rate of positive change was significantly different in the V-LSO group (LS angle: $41.94 \%$ vs. $61.54 \%$ vs. $83.87 \%$; $\mathrm{p}=0.003)$.

Conclusion The newly developed LSO showed no difference regarding its effectiveness and compliance when compared with the existing LSO, but it was more effective in correcting lumbar lordosis.
\end{abstract}

Keywords Braces, Lordosis, Spine, Survey and questionnaire, Postoperative case

Received July 27, 2020; Revised August 14, 2020; Accepted August 24, 2020; Published online February 9, 2021

Corresponding author: Hee Seung Yang

Department of Rehabilitation Medicine, Veterans Health Service Medical Center, 53 Jinhwangdo-ro 61-gil, Gangdong-gu, Seoul 05368, Korea. Tel: +822-2225-1498, Fax: +82-2-2225-1579, E-mail: yang7310@naver.com

ORCID: Soo Woong Jang (https://orcid.org/0000-0002-9955-6265); Hee Seung Yang (https://orcid.org/0000-0003-2492-7065); Young Bae Kim (https:// orcid.org/0000-0003-3966-0949); Joo Chul Yang (https://orcid.org/0000-0002-4496-937X); Kyu Bok Kang (https://orcid.org/0000-0001-7974-7438); Tae Wan Kim (https://orcid.org/0000-0001-7650-3331); Kwan Ho Park (https://orcid.org/0000-0001-5489-9830); Kyung Soo Jeon (https://orcid.org/00000002-2282-2780); Hee Dong Shin (https://orcid.org/0000-0003-4639-3236); Ye Eun Kim (https://orcid.org/0000-0003-3357-7378); Han Na Cho (https:// orcid.org/0000-0003-0715-9826); Yun Kyung Lee (https://orcid.org/0000-0002-5665-7779); Young Lee (https://orcid.org/0000-0003-0178-0187); Seul Bin Na Lee (https://orcid.org/0000-0001-8684-5271); Dong Young Ahn (https://orcid.org/0000-0002-3925-9525); Woo Sob Sim (https://orcid. org/0000-0002-0760-3918); Min Jo (https://orcid.org/0000-0001-9370-4119); Gyu Jik Jo (https://orcid.org/0000-0003-2498-027X); Dong Bum Park (https://orcid.org/0000-0002-8273-1872); Gwan Su Park (https://orcid.org/0000-0001-7681-7509).

(c) This is an open-access article distributed under the terms of the Creative Commons Attribution Non-Commercial License (http://creativecommons.org/ licenses/by-nc/4.0) which permits unrestricted noncommercial use, distribution, and reproduction in any medium, provided the original work is properly cited. Copyright (C) 2021 by Korean Academy of Rehabilitation Medicine 


\section{INTRODUCTION}

The traditional decompression and fusion procedure of the lumbar spine has been steadily increasing recently, and postoperative bracing (lumbosacral orthosis [LSO]) is commonly used after surgical treatment of lumbar degenerative conditions [1-3]. A previous study showed that $56 \%-59 \%$ of surgeons routinely consider postoperative bracing after at least one type of lumbar procedure [4,5]. An LSO is used to reduce pain and employed as a nonsurgical treatment of the spine by immobilizing a motion segment and unloading the forces on that spine segment by serving as a kinesthetic reminder and elevating intraabdominal pressure [6,7]. Despite its beneficial effects, it has some disadvantages. Immobilization induced by LSO may cause weakness in the back muscles and other low back pain [7-12]. In addition, skin-related complications such as pressure sores and wound problem can occur, and patients may complain of discomfort when wearing LSO. Considering these points, our orthosis and prosthesis center developed a new LSO (V-LSO) to help postoperative patients with lumbar degenerative conditions.

Two existing LSOs, namely, the classic lumbosacral corset and Cybertech spine brace (Bio Cybernetics International, Pasadena, CA, USA), were selected for comparison with the newly developed LSO. The classic LSO has been used by several surgeons for postoperative immobilization, but fitting it generally requires more than one visit to a skilled orthotist and adjusting it by oneself is difficult. Moreover, the pressure tends to be concentrated on the three buckles located in the front if not applied evenly. The Cybertech spine brace was made more comfortable to fit and easy to wear without assistance, but it is made of soft materials and has a smaller width to accommodate pressure [13]. To compensate for the shortcomings of the existing LSO, our orthosis and prosthesis center developed a new LSO to improve the comfort of the wearer and enhance its effectiveness. The V-LSO has a system without buckles that can be tightened by the patient independently, so it can apply pressure evenly and widely and it is easy to wear.

This study aimed to compare the convenience and effectiveness of existing LSOs (classic LSO and Cybertech) and the V-LSO.

\section{MATERIALS AND METHODS}

\section{Participants}

Between May 2019 and November 2019, 90 patients with degenerative lumbar spine disease scheduled for elective lumbar surgery such as laminectomy, discectomy, and posterior spinal instrumented fusion (PSIF) in the Departments of Orthopedic Surgery and Neurosurgery were enrolled in this study. Other inclusion criteria were as follows: age $>65$ years with lumbar degenerative disease with no neurological abnormalities and ability to walk with or without walking aids such as cane or walker. The exclusion criteria were as follows: patients with cognitive disorder; patients who could not complete the questionnaire; patients with a history of lumbar surgery; patients undergoing treatment for trauma or infection, compression fracture, spinal cancer, or metastatic cancer; and patients with systemic infection.

A total of 90 patients undergoing lumbar surgery for lumbar degenerative conditions were enrolled to participate in the study. One patient who could not continue the follow and another patient with cardiovascular disease were ex-

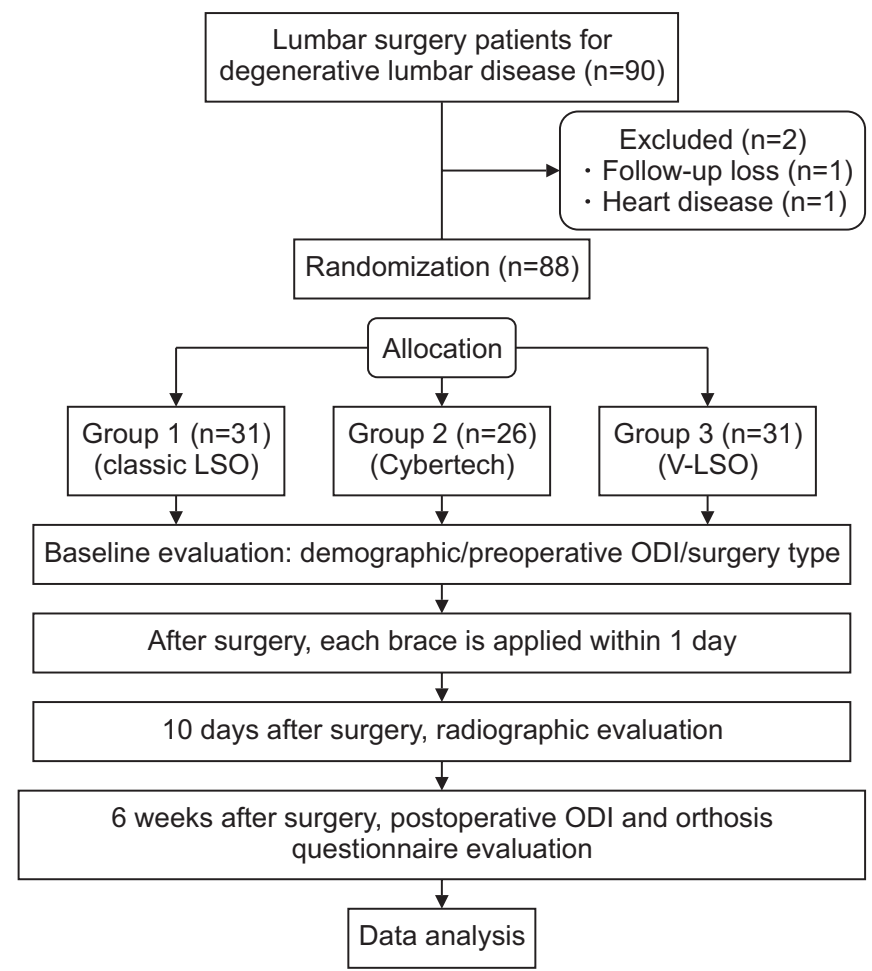

Fig. 1. Flowchart of the study. LSO, lumbosacral orthoses; V-LSO, a newly developed LSO; ODI, Oswestry Disability Index. 


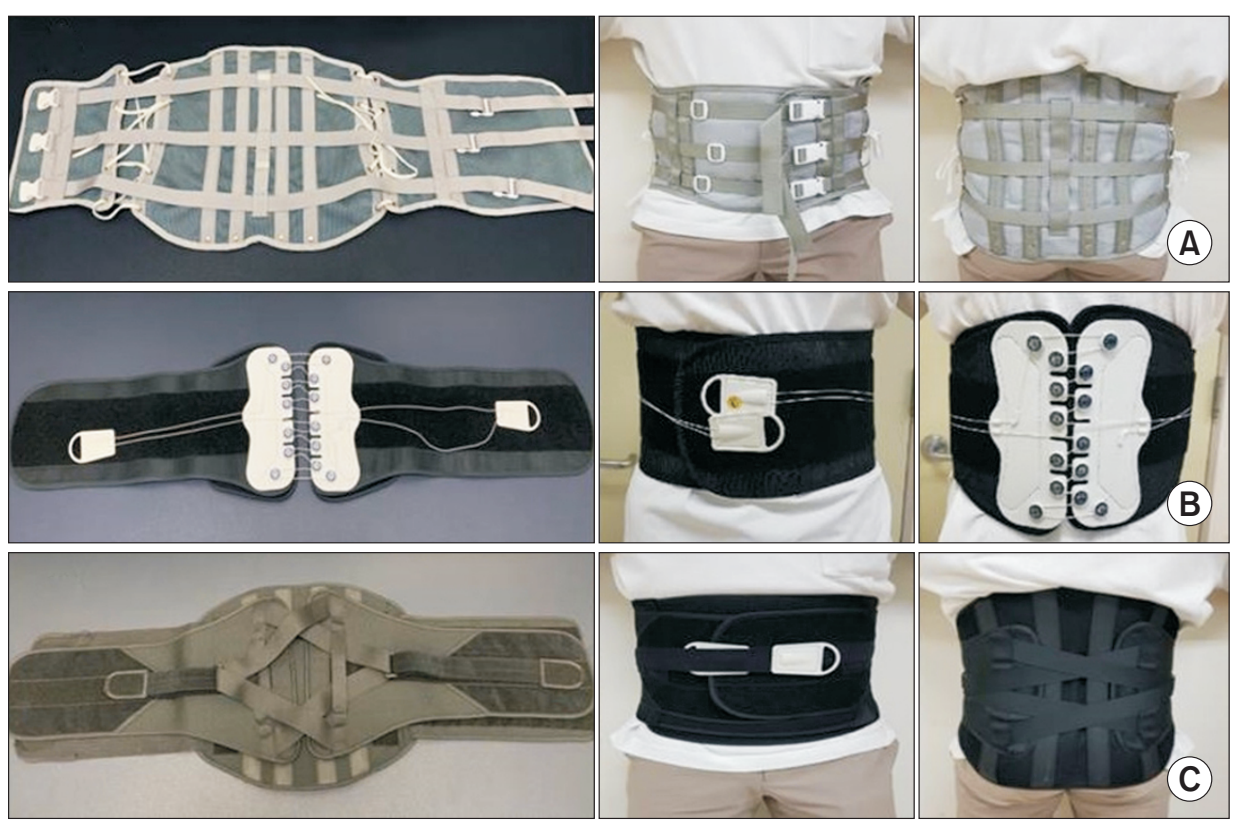

Fig. 2. The three types of lumbosacral orthoses (LSO): (A) classic lumbosacral corset, (B) Cybertech spine brace, and (C) a newly developed LSO (V-LSO).

cluded. Thus, data of a total of 88 patients were analyzed. For randomization, three types of LSO were provided depending on the time of patient registration and each LSO was applied for 6 weeks from the day of provision. Participants were randomized into three groups according to the types of LSO allocation: classic LSO group $(n=31)$, Cybertech group ( $n=26)$, and V-LSO group ( $n=31$ ) (Fig. 1).

\section{Intervention}

LSO can be rigid and flexible based on their material composition. Clinically, rigid LSO showed superior healing effect than flexible ones [14]. However, the use of rigid LSO has low compliance rate because of impaired respiration and the cumbersome nature of the LSO [6]. On the contrary, the flexible LSO are easy to move and wear as they have less movement restriction than rigid LSO [15]. Classic LSO are semi-rigid, have four plastic backstays, and can be fastened and tightened with straps and three buckles. The Cybertech brace has heat-molded back frame and two-hand pull system to compress it. The V-LSO is consists of inner and outer braces. The V-LSO is generally provided with a combination of inner and outer, as shown in Fig. 2C, and is worn in the same way as Cybertech. The inner brace has four plastic back panels and front abdomen support. The outer brace is made of mesh materials and has a self-tighten pulley system. The outer brace comes in large, medium, and small sizes, so different sizes of brace can be used depending on the patient's physique. Each brace is basically attached to each

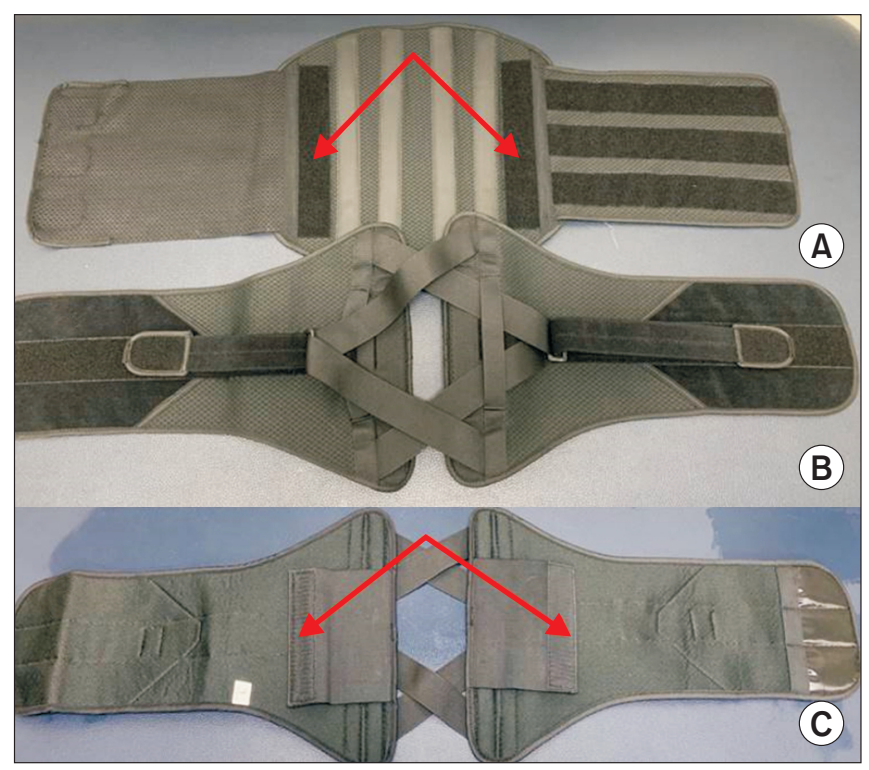

Fig. 3. The three types of lumbosacral orthoses (LSO) braces: (A) classic LSO, (B) Cybertech, and (C) a newly developed LSO (V-LSO). Each brace is basically attached to each other by Velcro corresponding to the red arrow, and it is recommended to be used in a combined form.

other by Velcro corresponding to the red arrow of Fig. 3, and it is recommended to be used in a combined form. However both the outer and inner can be worn alone by patients with mild symptom. In this study, the inner and outer braces were combined. The three LSO types are shown in Fig. 2, and the two components of the V-LSO are shown in Fig. 3. 

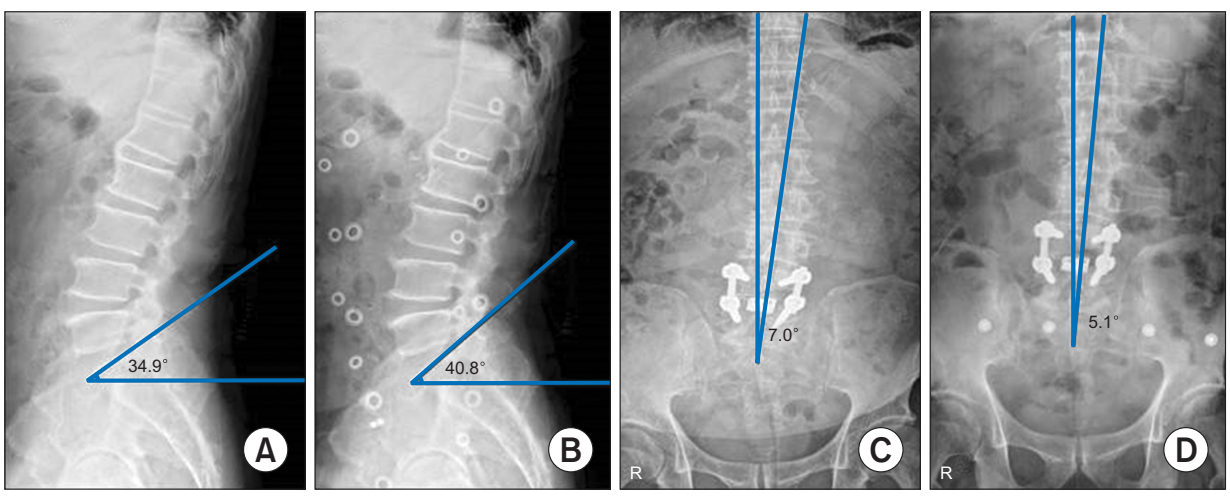

Fig. 4. Plain lumbar radiographs of lateral views (A, B) and anteroposterior views $(C, D)$ after 10 days of surgery with and without LSO. The LS angle and frontal imbalance were compared using radiograph data.

\section{Assessment}

All patients in the three groups wore LSO most of the time for 6 weeks after surgery, except during hygiene activities, sleep, and wound dressing.

All patients were assessed by plain lumbar radiography (anteroposterior and lateral views) after 10 days of surgery with and without LSO. The LS angle (mean value of the normal range, $41.1^{\circ} \pm 7.7^{\circ}$ ) and frontal imbalance were compared using radiograph data (Fig. 4). The LS angle was measured from the lumbar plain radiographs (lateral view) using Ferguson's technique, and it was defined as the angle that formed between the plane of the superior surface of the S-1 [16]. The LS angle is important in evaluating a patient's lumbar lordosis that may cause low back pain, disability, or degenerative disorder [16-21]. Frontal imbalance was defined based on the angle between the line passing through the endplate centers and the vertical gravitational line and measured from plain lumbar radiographs (anteroposterior view). This means that the global spine shape was straightened because of an increase in the abdominal pressure induced by the LSO [22]. In this study, the change in the LS angle and frontal imbalance towards the reference value (LS angle mean value of the normal range, $41.1^{\circ} \pm 7.7^{\circ}[16]$; frontal imbalance, $0^{\circ}$ ) was defined as positive change with and without LSO, conversely away from reference value is defined as negative change.

To exclude the effect of surgery on the satisfaction of using the LSO, all patients completed the Oswestry Disability Index (ODI) preoperatively, and at the sixth postoperative week, follow-up ODI assessment and orthosis questionnaire were completed. ODI is a good tool for measuring patient's low back functional disability. It consists of 10 questions, with a total score of 50 points, but if one question about sex life is missed, the scores are
Orthosis questionnaire

1 - strongly disagree; 2 - disagree; 3 - neutral; 4 - agree; 5 - totally agree

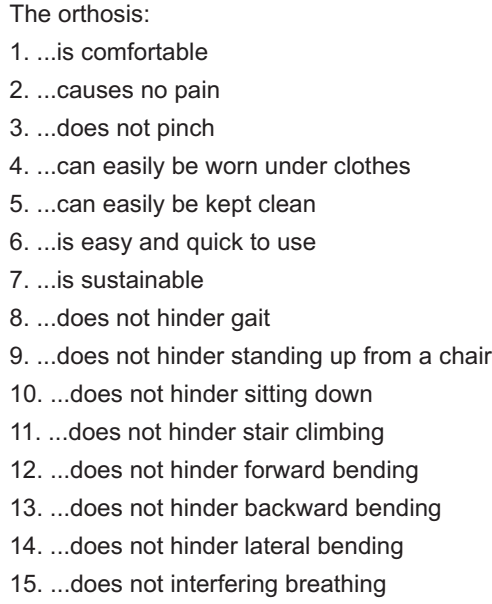

Fig. 5. The orthosis questionnaire consists of 15 questions, including whether the patient is comfortable, whether the orthosis interfered with movement, and whether breathing is uncomfortable.

converted to percentage [23,24]. Each question is given 5 points: the closer the score to 5 points, the more uncomfortable and severe is the functional disability.

The orthosis questionnaire consists of 15 questions, including whether the patient is comfortable, whether the orthosis interfered with movement, and whether breathing is uncomfortable. The orthosis questionnaire has a total score of 75 points, with 5 points per question. A score of 1 point means very uncomfortable, and 5 points means very convenient. Thus, a higher total score indicates that the LSO is easier and comfortable to use [25] (Fig. 5).

\section{IRB approval}

This study was approved by the Institutional Review 
Board of Veterans Health Service Medical Center (No. 2019-01-042). All patients signed an informed consent form.

\section{Statistical analysis}

Statistical analyses were performed using R software version 3.6.3 (R Foundation, Vienna, Austria). All data are presented as mean \pm standard deviation or number with percentage. Demographic characteristics (sex, age, body mass index [BMI], surgery type, and level), LS angle, and frontal imbalance and ODI and orthosis questionnaire results were compared using Fisher exact test or chisquare test for categorical variables, and one-way analysis of variance was used for continuous variables among the three groups. The level of statistical significance was set at $\mathrm{p}<0.05$.

\section{RESULTS}

\section{Characteristics of the study population}

Of the total 88 patients, 74 were men and 14 were women, with an average age of $71.56 \pm 8.03$ years, average admission duration of $16.14 \pm 14.43$ days, and average BMI of $25.51 \pm 3.60 \mathrm{~kg} / \mathrm{m}^{2}$. The demographics and characteristics of the three groups were analyzed and results shown in Table 1. No significant difference was found in the sex ratio ( $\mathrm{p}=0.445)$, age (Classic LSO vs. Cybertech vs. V-LSO, $70.61 \pm 9.15$ vs. $71.54 \pm 9.80$ vs. $72.55 \pm 5.16$ years; $\mathrm{p}=0.651)$, admission duration ( $17.90 \pm 13.70$ vs. $12.04 \pm 8.51$ vs. $18.48 \pm 21.09$ days; $\mathrm{p}=0.245)$, and BMI $(26.01 \pm 3.27$ vs. $25.73 \pm 3.98$ vs. $\left.24.79 \pm 3.56 \mathrm{~kg} / \mathrm{m}^{2} ; \mathrm{p}=0.379\right)$ were found among the three groups. When patients were divided into decompression alone and combination decompression and fusion, no significant difference was found among three groups ( $22: 9$ vs. $22: 4$ vs. $25: 6 ; p=0.428$ ). No significant statistical difference was also noted when the surgical level was divided into single and multiple levels (16:15 vs. $15: 11$ vs. $17: 14 ; \mathrm{p}=0.899$ ).

Overall, no significant statistical differences in the demographics and characteristics were observed among the three groups.

\section{Comparison of the radiographic findings}

Differences in the LS angle and frontal imbalance with and without LSO among three groups are presented in Table 2. No significant difference was found between the three groups in terms of the LS angle with LSO $\left(30.31^{\circ} \pm 7.21^{\circ}\right.$ vs. $27.60^{\circ} \pm 7.99^{\circ}$ vs. $\left.29.49^{\circ} \pm 5.58^{\circ} ; p=0.334\right)$, LS angle without LSO $\left(30.02^{\circ} \pm 8.20^{\circ}\right.$ vs. $28.48^{\circ} \pm 6.10^{\circ}$ vs. $31.91^{\circ} \pm 5.22^{\circ} ; \mathrm{p}=0.086$ ), frontal imbalance without LSO $\left(3.51^{\circ} \pm 2.31^{\circ}\right.$ vs. $2.60^{\circ} \pm 2.06^{\circ}$ vs. $\left.2.88^{\circ} \pm 2.31^{\circ} ; \mathrm{p}=0.291\right)$, and frontal imbalance with LSO $\left(2.87^{\circ} \pm 2.12^{\circ}\right.$ vs. $2.69^{\circ} \pm 1.71^{\circ}$ vs. $\left.2.34^{\circ} \pm 1.41^{\circ} ; \mathrm{p}=0.494\right)$. When the change in the LS angle and frontal imbalance towards the reference value (LS angle mean value of the normal range, $41.1^{\circ} \pm 7.7^{\circ}[16]$; frontal imbalance, $0^{\circ}$ ) was defined as positive change with and without LSO, the ratio of the positive change in the LS angle was significantly different in the V-LSO

Table 1. Demographics and characteristics

\begin{tabular}{|c|c|c|c|c|}
\hline & Classic $(n=31)$ & Cybertech $(n=26)$ & V-LSO $(n=31)$ & p-value \\
\hline Sex & & & & 0.445 \\
\hline Male & $28(90.62)$ & $22(84.62)$ & $24(78.12)$ & \\
\hline Female & $3(9.68)$ & $4(15.38)$ & $7(22.58)$ & \\
\hline Age (yr) & $70.61 \pm 9.15$ & $71.54 \pm 9.80$ & $72.55 \pm 5.16$ & 0.651 \\
\hline Admission duration (day) & $17.90 \pm 13.70$ & $12.04 \pm 8.51$ & $18.48 \pm 21.09$ & 0.245 \\
\hline $\operatorname{BMI}\left(\mathrm{kg} / \mathrm{m}^{2}\right)$ & $26.01 \pm 3.27$ & $25.73 \pm 3.98$ & $24.79 \pm 3.56$ & 0.379 \\
\hline Surgery type & & & & 0.428 \\
\hline Decompression without fusion & $22(70.97)$ & $22(84.62)$ & $25(80.65)$ & \\
\hline Interbody fusion & $9(29.03)$ & $4(15.38)$ & $6(19.35)$ & \\
\hline Surgery level & & & & 0.899 \\
\hline Single level & $16(51.61)$ & $15(57.69)$ & $17(54.84)$ & \\
\hline Multilevel & $15(48.39)$ & $11(42.31)$ & $14(45.16)$ & \\
\hline
\end{tabular}

Values are presented as mean \pm standard deviation or number (\%).

BMI, body mass index; V-LSO, a newly developed lumbosacral orthoses. 
Table 2. Comparison of radiographic findings, ODI and orthosis questionnaire

\begin{tabular}{|c|c|c|c|c|}
\hline & Classic $(n=31)$ & Cybertech $(n=26)$ & V-LSO $(n=31)$ & p-value \\
\hline \multicolumn{5}{|l|}{ LS angle } \\
\hline No brace & $30.31 \pm 7.21$ & $27.60 \pm 7.99$ & $29.49 \pm 5.58$ & 0.334 \\
\hline Brace & $30.02 \pm 8.20$ & $28.48 \pm 6.10$ & $31.91 \pm 5.22$ & 0.086 \\
\hline \multicolumn{5}{|l|}{ Frontal imbalance } \\
\hline No brace & $3.51 \pm 2.31$ & $2.60 \pm 2.06$ & $2.88 \pm 2.31$ & 0.291 \\
\hline Brace & $2.87 \pm 2.12$ & $2.69 \pm 1.71$ & $2.34 \pm 1.41$ & 0.494 \\
\hline LS angle change & & & & $0.003^{*}$ \\
\hline Negative change & $18(58.06)$ & $10(38.46)$ & $5(16.13)$ & \\
\hline Positive change & $13(41.94)$ & $16(61.54)$ & $26(83.87)$ & \\
\hline Frontal imbalance & & & & $0.048^{*}$ \\
\hline Negative change & 9 (29.03) & $16(61.54)$ & $14(45.16)$ & \\
\hline Positive change & $22(70.97)$ & $10(38.46)$ & $17(54.84)$ & \\
\hline Preoperative ODI & $51.43 \pm 14.10$ & $49.83 \pm 15.61$ & $57.75 \pm 17.10$ & 0.128 \\
\hline Postoperative ODI (6 weeks) & $39.31 \pm 18.35$ & $33.95 \pm 17.47$ & $38.32 \pm 25.06$ & 0.595 \\
\hline Orthosis questionnaire & $58.06 \pm 9.88$ & $63.58 \pm 11.84$ & $59.81 \pm 11.30$ & 0.167 \\
\hline
\end{tabular}

Values are presented as mean \pm standard deviation or number (\%).

ODI, Oswestry Disability Index; LS, lumbosacral; V-LSO, a newly developed lumbosacral orthoses.

${ }^{*} \mathrm{p}<0.05$.

group (LS angle $41.94 \%$ vs. $61.54 \%$ vs. $83.87 \%$; $\mathrm{p}=0.003$ ). Moreover, significant difference was noted in the frontal imbalance in the classic group (frontal imbalance, $70.97 \%$ vs. $38.46 \%$ vs. $54.84 \%$; $\mathrm{p}=0.041$ ).

Results of the comparison between the ODI and orthosis questionnaire

Differences in the ODI before and after surgery in all groups were statistically significant $(51.43 \pm 14.10$ vs. $39.31 \pm 18.35, \mathrm{p}=0.001 ; 49.83 \pm 15.61$ vs. $33.95 \pm 17.47$, $\mathrm{p}=0.002 ; 57.75 \pm 17.10$ vs. $38.32 \pm 25.06, \mathrm{p}=0.015)$. No statistically significant differences were found in the preoperative ODI ( $51.43 \pm 14.10$ vs. $49.83 \pm 15.61$ vs. $57.75 \pm 17.10$; $\mathrm{p}=0.128)$, ODI at the sixth postoperative week $(39.31 \pm 18.35$ vs. $33.95 \pm 17.47$ vs. $38.32 \pm 25.06$; $\mathrm{p}=0.595$ ), and the orthosis questionnaire results $(58.06 \pm 9.88$ vs. $63.58 \pm 11.84$ vs. 59.81 $\pm 11.30 ; \mathrm{p}=0.167$ ) (Table 2).

\section{DISCUSSION}

In this study, the effectiveness of three types of LSO applied within 1 day after lumbar surgery was compared. No significant differences in the LS angle, frontal imbalance, preoperative ODI, ODI at the sixth postoperative week, and orthosis questionnaire results were found among the LSO. However, in a comparison of the ratio of patients whose LS angle and frontal imbalance were closer to normal after the application of an LSO, the V-LSO was found to achieve better correction of the LS angle than the other LSO. This suggests that the V-LSO applies pressure throughout the abdomen and the back more evenly and supports the back and flank more effectively than the existing LSO.

Tuong et al. [22] investigated 28 healthy adults wearing semi-rigid LSO, and the radiographic findings confirmed that the LSO tended to reduce vertebral mobility and discal deformations mainly at the upper segments (L1-L3). Moreover, Utter et al. [26] showed that intervertebral motion reduction effect was confirmed in 10 healthy adults by videofluoroscopic analysis. The trend of lordosis correction effects confirmed by radiography in the present study was the same as in these previous studies.

In the present study, significant differences were found between preoperative and postoperative ODI among the three groups. These were thought to be caused by surgery, but no significant differences were observed in the ODI among the three groups, which was used to assess the functional aspect of the LSO. The mean ODI scores were improved by surgery; however, the postoperative effects of wearing LSO among the three types were not dif- 
ferent.

No significant differences were observed in the orthosis satisfaction questionnaire assessing compliance. These were also thought to occur because patients were not using all braces and all three braces were compared. The result of our study suggests that the newly developed LSO is functionally comparable with the existing LSO in terms of pain relief and convenience.

The reason why there were no significant postoperative differences between the postoperatively applied LSO may be related to why LSO was applied postoperatively in the first place. Previous studies have compared non-surgical and postoperative patients with LSO or without LSO and showed variable and controversial results $[1,3,5,27,28]$. Soliman et al. [1] analyzed 43 patients who underwent PSIF for lumbar degenerative conditions and reported that postoperative bracing did not show better improvement in the quality of life and pain relief. A meta-analysis has also shown that bracing after lumbar surgery for degenerative disease did not correlate with an improvement in outcome [29].

Other previous studies comparing LSO types focused on the healthy population, not patients $[22,26]$. A study compared LSO types in patients after surgery, but three LSOs were applied 3 months after surgery on the same day, unlike in our study where one LSO were applied within 1 day after surgery [13]. We believed that our results are meaningful: although previous studies mainly compared the effects of LSO between patients who used an LSO after surgery and those who were not, we compared three types of LSO among patients who required an LSO after a lumbar surgery.

This study has a few limitations. First, it is not a randomized controlled trial. Although randomization was necessary, patients were divided into three groups according to their enrollment dates, and the patients in each group were given the same type of LSO during the same period to prevent any patient complaints regarding the LSO design. Additionally, since patients scheduled for different types of lumbar surgery including laminectomy, discectomy, and PLIF were included rather than patients scheduled for one specific type of surgery, we could not accurately assess the effects of and patient satisfaction with the LSO. Finally, quantitative measurement tools such as using sensor for measuring the pressure within an LSO were not used in addition to radiography and questionnaire assessments. Nevertheless, this study is meaningful as it compared LSO types for early postoperative patients. Further studies are warranted on the reliability and validity of the sensor-based intra-abdominal measurement in healthy individuals wearing LSOs, and future research could include sensor-based measurements, radiography, and questionnaire assessments conducted in a larger cohort.

In conclusion, the newly developed LSO by our orthosis and prosthesis center showed no difference in its effectiveness and compliance compared with the existing LSOs. When the change in the LS angle toward the reference value was defined as a positive change with and without LSO, the ratio of the positive change was significantly different in the V-LSO group. This means that the V-LSO was more effective in correcting lumbar lordosis.

\section{CONFLICTS OF INTEREST}

No potential conflict of interest relevant to this article was reported.

\section{ACKNOWLEDGMENTS}

This study was supported by a Veterans Health Service Medical Center Research Grant, Republic of Korea (No. VHSMC-19023).

\section{AUTHOR CONTRIBUTION}

Conceptualization: Yang HS, Ahn DY. Methodology: Jang SW, Yang HS, Jo M. Formal analysis: Jang SW, Yang HS. Project administration: Jang SW, Kim YB, Yang JC, Kang KB, Kim TW, Park KH, Jeon KS, Shin HD, Kim YE, Cho HN, Lee YK, Lee Y, Lee SBN, Sim WS, Jo M, Jo GJ, Park DB, Park GS. Writing - original draft: Jang SW. Writing - review and editing: Jang SW, Yang HS. Approval of final manuscript: all authors.

\section{REFERENCES}

1. Soliman HA, Barchi S, Parent S, Maurais G, Jodoin A, Mac-Thiong JM. Early impact of postoperative bracing on pain and quality of life after posterior instrumented fusion for lumbar degenerative conditions: a randomized trial. Spine (Phila Pa 1976) 2018;43:155- 
60.

2. Machado GC, Ferreira PH, Yoo RI, Harris IA, Pinheiro MB, Koes BW, et al. Surgical options for lumbar spinal stenosis. Cochrane Database Syst Rev 2016; 11:CD012421.

3. Connolly PJ, Grob D. Bracing of patients after fusion for degenerative problems of the lumbar spine: yes or no? Spine (Phila Pa 1976) 1998;23:1426-8.

4. Bogaert L, Van Wambeke P, Thys T, Swinnen TW, Dankaerts W, Brumagne S, et al. Postoperative bracing after lumbar surgery: a survey amongst spinal surgeons in Belgium. Eur Spine J 2019;28:442-9.

5. Bible JE, Biswas D, Whang PG, Simpson AK, Rechtine GR, Grauer JN. Postoperative bracing after spine surgery for degenerative conditions: a questionnaire study. Spine J 2009;9:309-16.

6. Agabegi SS, Asghar FA, Herkowitz HN. Spinal orthoses. J Am Acad Orthop Surg 2010;18:657-67.

7. Nachemson A, Schultz A, Andersson G. Mechanical effectiveness studies of lumbar spine orthoses. Scand J Rehabil Med Suppl 1983;9:139-49.

8. Azadinia F, Ebrahimi E Takamjani, Kamyab M, Parnianpour M, Cholewicki J, et al. Can lumbosacral orthoses cause trunk muscle weakness? A systematic review of literature. Spine J 2017;17:589-602.

9. Cho KH, Beom JW, Lee TS, Lim JH, Lee TH, Yuk JH. Trunk muscles strength as a risk factor for nonspecific low back pain: a pilot study. Ann Rehabil Med 2014;38:234-40.

10. Lee JH, Hoshino Y, Nakamura K, Kariya Y, Saita K, Ito $\mathrm{K}$. Trunk muscle weakness as a risk factor for low back pain: a 5-year prospective study. Spine (Phila Pa 1976) 1999;24:54-7.

11. Pfeifer M, Kohlwey L, Begerow B, Minne HW. Effects of two newly developed spinal orthoses on trunk muscle strength, posture, and quality-of-life in women with postmenopausal osteoporosis: a randomized trial. Am J Phys Med Rehabil 2011;90:805-15.

12. Sato N, Sekiguchi M, Kikuchi S, Shishido H, Sato K, Konno S. Effects of long-term corset wearing on chronic low back pain. Fukushima J Med Sci 2012;58:60-5.

13. Krag MH, Fox MS J, Haugh LD. Comparison of three lumbar orthoses using motion assessment during task performance. Spine (Phila Pa 1976) 2003;28:2359-67.

14. Fujimoto Y, Sakai T, Sairyo K. What type of orthosis is optimal for conservative treatment of lumbar spon- dylolysis?: a biomechanical analysis. Spine Surg Relat Res 2019;4:74-80.

15. Cholewicki J, Lee AS, Peter Reeves N, Morrisette DC. Comparison of trunk stiffness provided by different design characteristics of lumbosacral orthoses. Clin Biomech (Bristol, Avon) 2010;25:110-4.

16. Hellems HK Jr, Keats TE. Measurement of the normal lumbosacral angle. Am J Roentgenol Radium Ther Nucl Med 1971;113:642-5.

17. Dillane JB, Fry J, Kalton G. Acute back syndrome: a study from general practice. Br Med J 1966;2:82-4.

18. Ferguson AB. The clinical and roentgenographic interpretation of lumbosacral anomalies. Radiology 1934;22:548-58.

19. Meschan I, Farrer-Meschan RM. Important aspects in the roentgen study of the normal lumbosacral spine. Radiology 1958;70:637-48.

20. Moreton RD, Winston JR, Bibey DE, Williams C. Radiologic considerations in preplacement examinations of the lumbar spine; summary of four thousand consecutive cases. Radiology 1954;63:667-72.

21. Okpala FO. Comparison of four radiographic angular measures of lumbar lordosis. J Neurosci Rural Pract 2018;9:298-304.

22. Tuong NH, Dansereau J, Maurais G, Herrera R. Threedimensional evaluation of lumbar orthosis effects on spinal behavior. J Rehabil Res Dev 1998;35:34-42.

23. Davidson M, Keating JL. A comparison of five low back disability questionnaires: reliability and responsiveness. Phys Ther 2002;82:8-24.

24. Fairbank JC. Oswestry disability index. J Neurosurg Spine 2014;20:239-41.

25. Curfs I, van Rooij W, Senden R, Grimm B, Van Hemert W. Evaluating the immobilization effect of spinal orthoses using sensor-based motion analysis. J Prosthet Orthot 2016;28:23-9.

26. Utter A, Anderson ML, Cunniff JG, Kaufman KR, Jelsing EJ, Patrick TA, et al. Video fluoroscopic analysis of the effects of three commonly-prescribed off-the-shelf orthoses on vertebral motion. Spine (Phila Pa 1976) 2010;35:E525-9.

27. Yao YC, Lin HH, Chang MC. Bracing following transforaminal lumbar interbody fusion is not necessary for patients with degenerative lumbar spine disease: a prospective, randomized trial. Clin Spine Surg 2018;31:E441-5. 
28. Yee AJ, Yoo JU, Marsolais EB, Carlson G, Poe-Kochert C, Bohlman $\mathrm{HH}$, et al. Use of a postoperative lumbar corset after lumbar spinal arthrodesis for degenerative conditions of the spine: a prospective randomized trial. J Bone Joint Surg Am 2008;90:2062-8.
29. Nasi D, Dobran M, Pavesi G. The efficacy of postoperative bracing after spine surgery for lumbar degenerative diseases: a systematic review. Eur Spine J 2020;29:321-31. 